\title{
Electronic Payment Systems Evaluation: A Case Study in Iran
}

\author{
Shiva Zokaee1, *Seyed Babak Ebrahimi1', Mostafa Ghazizadeh² \\ ${ }^{1}$ Iran University of Science and Technology, Tehran, Iran \\ 2University of Shahed, Tehran, Iran \\ *b_ebrahimi@iust.ac.ir
}

\begin{abstract}
As moving businesses from face-to-face trading, mail order and telephone order to electronic commerce over open networks such as the Internet, there be an exponentially growth in electronic payment transactions. Therefore, monitoring and evaluating the current electronic payment systems greatly affects the efficiency of money transactions, trades and, finally, the overall economy of the countries. In this paper, the Iranian e-payment systems are examined as a special case. The aim is to examine and evaluate the current epayment systems, and rank they based on the experts opinions. Considering the nature of the gathered data, the analytic hierarchy process (AHP), as a decision-making method, is used to evaluate the data. The findings of this research are intended to be useful for both academic researchers and companies planning to adopt or to improve an electronic payment system.
\end{abstract}

\section{Key words: Electronic payment system, Internet, E-commerce, Analytic hierarchy process}

\section{Introduction and Literature Review}

The worldwide proliferation of the Internet led to the birth of electronic commerce, a business environment that allows the electronic transfer of transactional information. Electronic commerce (EC) flourished because of the openness, speed, anonymity, digitization and global accessibility characteristics of the Internet, which facilitated real-time business activities, including advertising, querying, sourcing, negotiation, auction, ordering and paying for merchandise (Yu et al., 2002). According to Tsiakis and Sthephanides (2005) the critical factor of success for every commercial entity to implement and operate an electronic business mechanism is money flow, material flow and information flow in commerce process. In this era, payment systems play a major part in the conduct of a country's monetary policy, financial sector and economic development (Johnson, 1998; World Bank, 1990). They improve macroeconomic management, release funds from the clearing and settlement functions for more productive use, and reduce float levels, improving the control of monetary aggregates. Moreover, firms in different economic sectors use the payment system to transfer funds and to provide competitive financial services (Khiaonarong, 2000). According to Yu et al. (2002), when companies enter electronic commerce market, choosing an electronic payment system that works well with the way they run their business that is both popular and safe is a major concern.

There are researches in e-payment domain that related of which to our research will be addressed here. Addressing the rapid growth of internet access in United Kingdom, Credé (1998) stated that the proliferation of the volume of business transacted through the internet would have exponentially growth in the first decade of the third millennium. He mentioned the effect of e-payment systems on the UK economy, and examined the pros and cons of the common e-payment systems in the UK, like debit and credit cards. Furthermore, they suggested some alternative e-payment systems that they believe outperform the current systems. Khiaonarong (2000) examined the creation of modern electronic payment systems in Thailand and concluded that this creation has helped facilitate the turnover of funds in the economy, while the use of information technology in current payment arrangements helped reduce human intervention and default cheques and has helped strengthen the country's capabilities and competitiveness in providing financial services. Yu et al., (2002) explored the advantages and limitations of several different electronic payment systems including online credit card payment, electronic cash, electronic checks and small payments. After analyzing and comparing these types of payment systems, they concluded that in the future, the use of virtual credit cards would escalate. Furthermore, smart cards will replace traditional electronic cash in the market. They also proposed that electronic checks are suitable for corporations and governments because their direct 
cost is high. In addition, they concluded that pay-per-click and per-fee-links would definitely become online trends for transactions.

Tsiakis and Sthephanides (2005) studied concept of security, trust and their affects in electronic payments. Their study implicated that these issues are essential for every electronic payment mechanism in order to be accepted and established as a common medium of financial transactions. Hung et al. (2006) surveyed the factors that determine the publics' acceptance of online tax filing and payment system (OTFPS) in Taiwan. Investigating relevant previous studies, they identified the determinants for acceptance of the OTFPS. Then, they examined the casual relationship among the variables of acceptance behavior for the OTFPS. Using data collected from 1099 usable responses, they indicated that the proposed model explained up to $72 \%$ of the variance in behavioral intention. In addition, the important determinants of user acceptance of the OTFPS are perceived usefulness, ease of use, perceived risk, trust, compatibility, external influences, interpersonal influence, self-efficacy and facilitating condition. Jing (2009) examined the security of on-line payments. He, also, surveyed the common on-line electronic payment system and focused on the internet bankcard payment system, electronic-cash internet payment system, e-purse internet payment system and electronic check internet payment system. In his attempt, he counted the safety factors as the integrity of the information, the validity of information, the non-repudiation of information, the authenticity of the transaction status and the reliability of the system. Finally, he proposed a strategy of e-commerce security.

Review of literature shows that e-payment systems in Iran has not gained attention by researchers. This research paper aims to define and analyze different types of electronic payment systems in Iran as a special case. In addition, using analytic hierarchy process method, data and information gathered from Iranian experts are processed and the e-payment systems in Iran are prioritized to depict the current situation and even use the findings to plan the people need. Furthermore, this research gives an insight to the researchers who are not familiar with Iranian common e-payment systems and their importance in Iran money transactions. Besides, findings of this research are intended to be useful for both academic researchers and companies planning to adopt or to improve an electronic payment system. The rest of this paper is organized as follows. Section 2 explores research methodology. Common e-payment systems in Iran are described in section 3 and section 4 describe assessment criteria for evaluation of E-payment systems. Section 5 presents research results and finally the paper is closed with some concluding remarks in section 6 .

\section{Methodology}

Data for this study is gathered via a combination of interviews and questionnaires. We first interviewed 8 experts in the field of electronic commerce and electronic banking. These experts were four IT managers (or a representative, for example assistant manager, if the manager was not available at the time of the interview) in four Iranian banks which propose electronic banking services to their customers and four IT managers in four Iranian e-retailers. During the interviews, we sought general information from the managers about epayment systems in Iran, and asked them to discuss customers' preference and criteria for e-payment system selection. The main questions the experts answered were as:

- What are common e-payment methods in Iran?

- Which criteria exist for evaluation of e-payment systems?

- Which other criteria can be adopted to evaluate e-payment systems?

- Is there kept a history of the money transactions data conducting through the e-payment systems?

- What importance weights do they assign to each of the e-payment systems as an expert?

Examining previous related works and using data gathered by interviews, evaluation criteria for e-payment systems needed the hierarchy problem construction. Consequently, in the next step, using a questionnaire, we asked 36 experts (include eight IT managers introduced above, 14 specialists in the field of EC and 14 specialists who were employed by e-retailers) to compare the elements of a particular level with respect to a specific element in the immediate upper level. Using data collected by questionnaires, we made pair-wise comparisons and constructed judgment matrix. In the next sections of this research, results are presented. 


\section{Results}

E-Payment Systems in Iran: Here, according to interviews, e-payment systems in Iran are discussed and some statistics are presented. There are 5 types of e-payments in Iran as:

Electronic money: There is still no comprehensive definition of e-money but surveying in current definitions, e-money could be defined as follow: "Money that is moving as electronic currency and can be saved or represented as smart cards or electronic wallets. It can also be used in sale terminals, or person to person, or be flowed, or expend to banks, or other distributors of e-money through phone lines." From the above, it can be concluded that e-money is a payment mechanism for reserved or prepaid value, which is saved in an electronic instrument and is possessed by the consumer. Each time the electronic money user connects to the electronic or internet payment-terminals to pay for the service or product she/he has used or purchased, her/his credit reduces. E-money is the most important tool to apply digital technology in economic context and can be used as bankcards, transferring money in internet, salary and wage systems and other concepts in e-commerce.

Credit card: Credit card is a plastic card, which contains name and identity of the owner on its surface. There exists a magnetic tape which contains identity and owner address, in the back. Computerized financial systems like ATM use this information to distinguish identity of card owner when drawing money. Bank or issuing institute confirms the credit to almost 50000\$. Even if the owners have no money in their account, to a distinguished level, they can buy or get money. However, they have to liquidate to a certain time. Commonly customers have to pay a rate near to $2 \%$ in month for used credit. Samin card, which yet is not popular, is a kind in Iran. Credit cards are rarely used and are not more than $3 \%$ of active bank network cards. Regarding to importance of credit cards in developing small facilities for all citizens and the affect on expanding sale terminals in malls, Islamic Republic of Iran Central Bank, cooperating with bank network, is willing to develop issuing and strategic plans of credit cards. By the way, aiming at popularizing e-payment and substituting it to cash payment, Central Bank of Islamic Republic Iran has enacted rules.

Debit card: Debit card is the commonest way to pay in Iran. Using this payment channel, one should settle money to his /her account and then use it. The account will be indebtedness after off taking and lets he/she to pay or draw money until there still exist money in account. In fact, it is like a currency account. Using Debit cards in Iran goes to the year 1991 and the early use of Sepah ATMs, which were the first machine to take money from. In recent years, almost all the banks are equipped with this system. The aim is to develop electronic machines instead of branch box offices and give cash to customers. Card bank networks in Islamic Republic of Iran launched in year 2001 to transfer information among banks as an integrated system in the whole country terminals named as Shetab. Official statistics shows there are 6438936 issued cards in Tehran and 10683892 issued cards in other provinces. Surveying of bank and insurance service of Economic Abrar statistics shows there would be a great increase in number of cards comparing to last month, till the end of September 2008 and it would be 17122828 cards which are 2534445 cards for private banks and 14588383 cards for public banks. The developing situation of e banking in Iran is presented in Table 1.

Charging card: Credits are paid at the beginning of each period, and the owner should pay back the money at the end of that period. These kinds of cards have a fixed charging cost.

Electronic cheque: Electronic cheque is a developed format of paper cheque. In general, paper cheques are transferable when there are name, date and the price written on them. In electronic format, one just has to write the price and the rest is done by related devices, and even there is no need for any papers. Now, payment system LML is a terminal to converse paper cheque to electronically ones. The method is as follow: Costumer gives the paper cheque, and then the cheque-reading device converts the information of his/her account and electronic signature to electronic actions. Using e- cheque reduces the costs because of no need to papers and post. In Iran, this method is rarely used.

Assessment Criteria for Evaluation of E-Payment Systems: Examining previous related researches and experts opinions, we defined criteria for e-payment systems' evaluation. Because of the importance of 
security in e-payment systems, we divided the criteria into two main categories: The socioeconomic and security criteria. In addition, both the categories are discussed as follows:

\section{Security criteria}

- Authority (C1): Also referred to as validity, authority is one of the most important criteria to be taken into consideration. The purpose is to verify the claimed identities of all parties involved and to prevent third parties from sabotaging information or making unauthorized transfers ( $\mathrm{Yu}$ et al., 2002).

- Privacy (C2): The purpose is to protect information that is sent via the Internet, and to prevent unauthorized personnel or company employees from accessing confidential information (Yu et al., 2002).

- Integrity (C3): This includes the prevention of tampered transactions, making mistakes when sending information and avoids accidentally sending a transaction twice, or accidentally sending of a transaction with false information, to prevent consumers and producers from denying their involvement in a transaction or from changing information in the transaction (Yu et al., 2002).

- Not be faked (C4): One of the security problems are faked monies and signs.

- Non-repudiation (C5): The electronic payment system must be designed in such a way that consumers and companies will be unable to deny their participation in a transaction if they were involved. Therefore, records of details, such as the time of the transaction, the information involved in the transaction etc. must be kept in a secure database (Yu et al., 2002).

- Anonymity (C6): A condition in which an individual's identity is unknown (Tsiakis and Sthephanides, 2005).

Table 1: E-banking status till end of March 2008

\begin{tabular}{llllll}
\hline \multirow{2}{*}{ Name of bank } & ATM & & \multicolumn{3}{l}{ POS } \\
\cline { 2 - 6 } & Exploited & $\begin{array}{l}\text { Under } \\
\text { construction }\end{array}$ & Buy Phase & Pos Market & $\begin{array}{l}\text { Magnetic + Smart } \\
\text { cards }\end{array}$ \\
\hline Saderat & 1474 & 32 & 500 & 18150 & 4000000 \\
Mellat & 1195 & 19 & 7 & 8400 & 1400000 \\
Sepah & 1100 & 130 & 0 & 23 & 4000000 \\
Melli & 1076 & 1412 & 500 & 421 & 4897000 \\
Keshavarzi & 729 & 426 & 0 & 10600 & 2234000 \\
Tejarat & 731 & 269 & 600 & 200 & 2474000 \\
Refah & 511 & 5 & 0 & 76 & 81000 \\
Eghtesad e Novin & 184 & 20 & 300 & 42000 & 881000 \\
Maskan & 122 & 250 & 250 & 16 & 213000 \\
Saman & 106 & 12 & 0 & 28369 & 206000 \\
Parsian & 98 & 2 & 50 & 59000 & 2642000 \\
Post Bank & 55 & 0 & 6 & 0 & 19000 \\
Pasargad & 54 & 6 & 35 & 475 & 41000 \\
Sanat o Maadan & 41 & 0 & 0 & 2200 & 15000 \\
Karafarin & 22 & 10 & 0 & 0 & 29000 \\
Sarmayeh & 17 & 3 & 0 & 0 & 210 \\
Tosee Saderat & 13 & 0 & 15 & 140 & 13000 \\
Total & 7645 & 2599 & 2263 & 170000 & 23500000 \\
\hline
\end{tabular}

Source: Http://novinbank.blogfa.com/post-77.aspx 


\section{Socioeconomic criteria}

- The cost of transactions (C7): This refers to the cost paid by the seller and buyer involved in the transaction. This can be divided into direct cost and indirect cost. In choosing the electronic payment system for small payments, the cost of the transaction will be a deciding factor (Yu et al., 2002).

- Reliability (C8): According to Wikipedia, the ability of a system performs its required functions under stated conditions for a specified period.

- Degree of acceptability (C9): The electronic payment system should be simple and user-friendly. The degree of user friendliness is a factor when consumers decide which system to use, especially for small payments (Yu et al., 2002).

- User range (C10): This refers to the range of users to which an electronic payment system is accessible. This includes whether the system is accessible in all countries of the world, to all ages (Yu et al., 2002).

\section{Evaluation by Using Analytic Hierarchy Process (AHP)}

AHP is one of the most popular decision making tools to formulate and analyze decisions. The technique is applied to rank a set of alternatives or to select the best in an alternative set. The ranking/selection is done with respect to an overall goal, which is broken down into a set of criteria. A brief discussion of AHP is provided in this section. More detailed description of AHP and application issues can be found in (Saaty, 1980). AHP has been applied to numerous practical problems in the last few decades (Shim, 1989).

Step 1: Structuring of the decision problem into a hierarchical model: It includes decomposition of the decision problem into elements according to their common characteristics and the formation of a hierarchical model having different levels. A simple AHP model has three levels (goal, criteria and alternatives). It is notable that criteria can be divided further into sub-criteria and sub-sub-criteria. Using the criteria mentioned in Section 5, the hierarchical model of the problem is as follows (Figure1):

\section{Figure 1. Hierarchical model of problem}

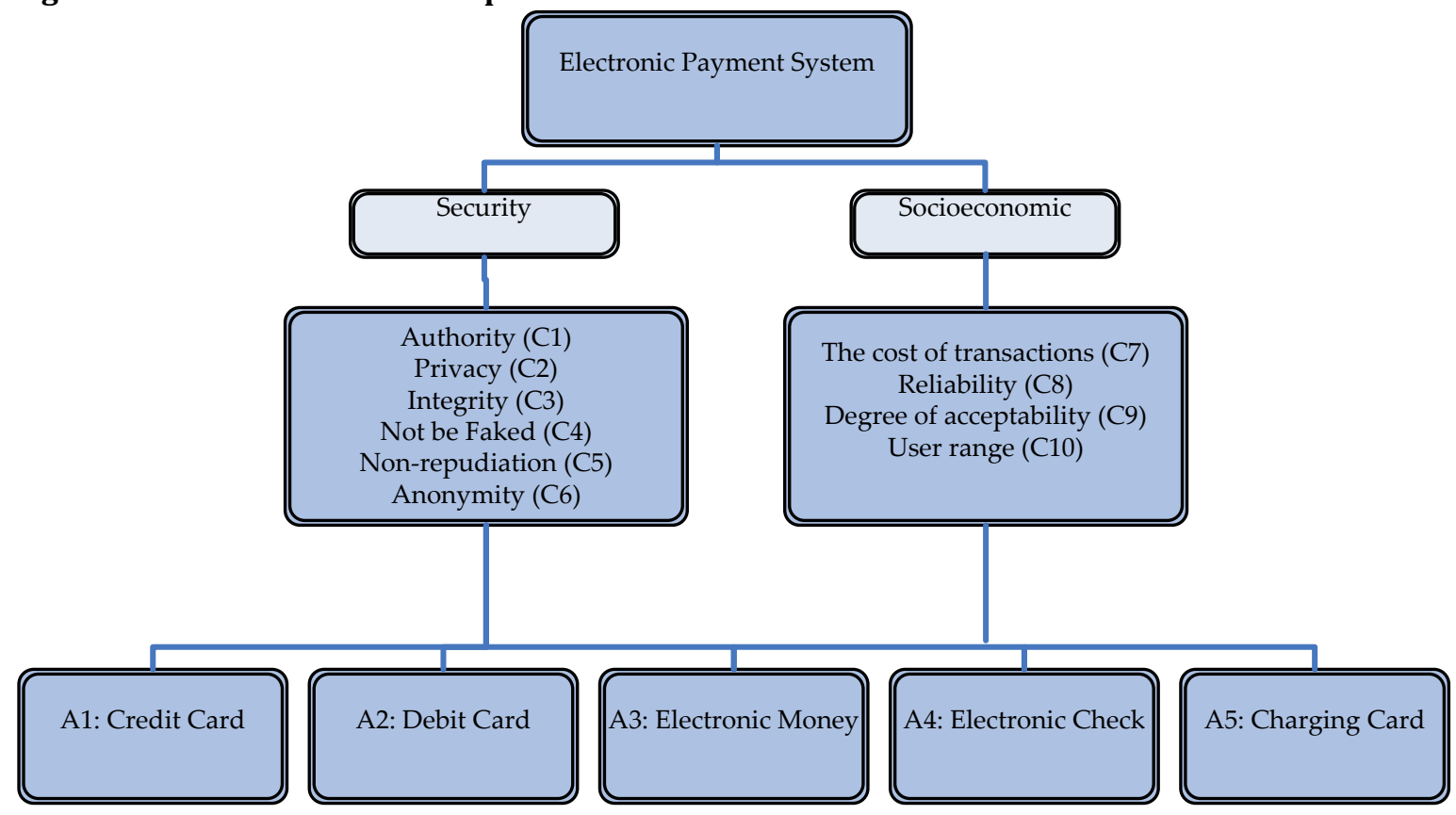

Step 2: Making pair-wise comparisons, obtaining the judgment matrix and calculating local weights: In this step, the elements of a particular level are compared with respect to a specific element in the immediate upper level. The resulting weights of the elements may be called the local weights (to be contrasted with final weights, discussed in Step 4). The opinion of a decision-maker (DM) is elicited for comparing the elements. 
Elements are compared pair-wise and judgments on comparative attractiveness of elements are captured using a rating scale ( 1 - 9 scale in traditional AHP). Usually, an element receiving higher rating is viewed as superior (or more attractive) compared to another one that receives a lower rating. The comparisons are used to form a matrix of pair-wise comparisons called the judgment matrix. It is notable that based on specialists' opinions; local weight of security criteria with regard to goal is equal to 0.6. Hence, this value is equal to 0.4 for the socioeconomic criteria.

Table 2: Comparison of criteria with respect to security

\begin{tabular}{llllllll}
\hline & $C_{1}$ & $C_{2}$ & $C_{3}$ & $C_{4}$ & $C_{5}$ & $C_{6}$ & Local Weight \\
\hline$C_{1}$ & 1.000 & 0.500 & 1.000 & 2.000 & 2.000 & 2.500 & 0.2019130 \\
$C_{2}$ & 2.000 & 1.000 & 2.000 & 3.000 & 1.500 & 3.000 & 0.2913110 \\
$C_{3}$ & 1.000 & 0.500 & 1.000 & 1.000 & 0.500 & 1.500 & 0.1309112 \\
$C_{4}$ & 0.500 & 0.333 & 1.000 & 1.000 & 1.000 & 0.500 & 0.1040740 \\
$C_{5}$ & 0.500 & 0.666 & 2.000 & 1.000 & 1.000 & 2.000 & 0.1662810 \\
$C_{6}$ & 0.400 & 0.333 & 0.666 & 2.000 & 0.500 & 1.000 & 0.1055090 \\
\hline
\end{tabular}

Table 3: Comparison of criteria with respect to socioeconomic

\begin{tabular}{llllll}
\hline & $C_{7}$ & $C_{8}$ & $C_{9}$ & $C_{10}$ & Local Weight \\
\hline$C_{7}$ & 1.000 & 2.000 & 3.000 & 3.000 & 0.44491782 \\
$C_{8}$ & 0.500 & 1.000 & 2.000 & 3.000 & 0.28789220 \\
$C_{9}$ & 0.333 & 0.500 & 1.000 & 0.750 & 0.12933240 \\
$C_{10}$ & 0.333 & 0.333 & 1.333 & 1.000 & 0.13785800 \\
\hline
\end{tabular}

Table 4: Comparison of e-payment systems with respect to $\mathbf{C 6}$

\begin{tabular}{lllllll}
\hline & $A_{1}$ & $A_{2}$ & $A_{3}$ & $A_{4}$ & $A_{5}$ & Local Weight \\
\hline$A_{1}$ & 1.000 & 0.750 & 2.000 & 2.500 & 3.000 & 0.288427128 \\
$A_{2}$ & 1.333 & 1.000 & 2.000 & 2.750 & 3.000 & 0.330016746 \\
$A_{3}$ & 0.500 & 0.500 & 1.000 & 1.500 & 2.000 & 0.168164521 \\
$A_{4}$ & 0.400 & 0.363 & 0.666 & 1.000 & 1.500 & 0.121015707 \\
$A_{5}$ & 0.333 & 0.333 & 0.5 & 0.666 & 1.000 & 0.092375898 \\
\hline
\end{tabular}

From judgment matrixes, local weights easily can be calculated. It should be noted that in this step, local weights of the elements are calculated using the eigenvector method (EVM). The normalized eigenvector corresponding to the principal eigenvalue of the judgment matrix provides the weights of the corresponding elements. Though EVM is followed widely in traditional AHP computations, other methods are also suggested for calculating weights, including the logarithmic least-square technique (LLST) (Crawford and Williams, 1985 and Lootsma, 1999) and goal programming (Bryson and Joseph, 1999).

Step 3. Aggregation of weights across various levels to obtain the final weights of alternatives: Once the local weights of elements of different levels are obtained as outlined in Step 2, they are aggregated to obtain final weights of the decision alternatives (elements at the lowest level). For example, the final weight of alternative $A_{i}$ is computed using the following hierarchical (arithmetic) aggregation rule in traditional AHP: 
Final weight of $A_{i}=\sum_{j=1}^{10}\left[\left(\begin{array}{c}\text { Local weight of } A_{i} \text { with } \\ \text { respect of criterion } C_{j}\end{array}\right) \times\left(\begin{array}{l}\text { Local weight of } \\ \text { criterion } C_{j}\end{array}\right)\right]$.

(1)

so

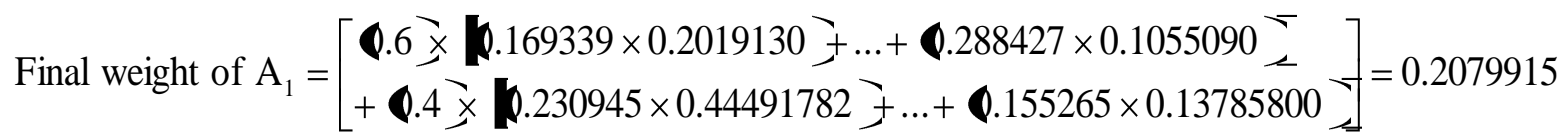

Finally Table 5 shows local weights of alternatives with respect to criteria

Table 5: Local weights of alternatives with respect to criteria

\begin{tabular}{llllll}
\hline & $A_{1}$ & $A_{2}$ & $A_{3}$ & $A_{4}$ & $A_{5}$ \\
\hline$C_{1}$ & 0.169339 & 0.201365 & 0.144586 & 0.322071 & 0.162640 \\
$C_{2}$ & 0.182874 & 0.201963 & 0.259570 & 0.210229 & 0.145365 \\
$C_{3}$ & 0.141270 & 0.141270 & 0.249206 & 0.326984 & 0.141270 \\
$C_{4}$ & 0.265834 & 0.261011 & 0.181437 & 0.112917 & 0.178802 \\
$C_{5}$ & 0.163194 & 0.147405 & 0.188390 & 0.346369 & 0.154641 \\
$C_{6}$ & 0.288427 & 0.330016 & 0.168164 & 0.121015 & 0.092375 \\
$C_{7}$ & 0.230945 & 0.225633 & 0.103999 & 0.103999 & 0.335400 \\
$C_{8}$ & 0.267164 & 0.288859 & 0.141465 & 0.110553 & 0.191980 \\
$C_{9}$ & 0.248393 & 0.236628 & 0.147726 & 0.118860 & 0.248393 \\
$C_{10}$ & 0.155265 & 0.148813 & 0.308595 & 0.262542 & 0.126480 \\
\hline
\end{tabular}

The final weights computed using (1) for the illustration is shown in Table 6.

Table 6: Final weights of alternatives

\begin{tabular}{llllll}
\hline & $A_{1}$ & $A_{2}$ & $A_{3}$ & $A_{4}$ & $A_{5}$ \\
\hline$C_{1}$ & 0.0205150 & 0.024394927 & 0.017517276 & 0.039018193 & 0.01970347 \\
$C_{2}$ & 0.0319639 & 0.035300426 & 0.45369358 & 0.036745212 & 0.02540785 \\
$C_{3}$ & 0.0110962 & 0.011096295 & 0.019574314 & 0.025683521 & 0.01109629 \\
$C_{4}$ & 0.0165998 & 0.016298675 & 0.011329725 & 0.007251034 & 0.01116518 \\
$C_{5}$ & 0.0162816 & 0.01470639 & 0.018795407 & 0.03455675 & 0.01542831 \\
$C_{6}$ & 0.0182565 & 0.020088995 & 0.010644297 & 0.007664005 & 0.00585043 \\
$C_{7}$ & 0.0411006 & 0.040155257 & 0.18506802 & 0.018508403 & 0.05969462 \\
$C_{8}$ & 0.0307657 & 0.033264106 & 0.01629067 & 0.01273094 & 0.02210747 \\
$C_{9}$ & 0.0212851 & 0.012241471 & 0.007642306 & 0.006148982 & 0.01285010 \\
$C_{10}$ & 0.0085617 & 0.008205995 & 0.017016854 & 01.014477354 & 0.00697432 \\
Sum & 0.2079915 & 0.216553501 & 0.182686007 & 0.202584394 & 0.19027808 \\
\hline
\end{tabular}

According to the last matrix, debit cards are the most preferred e-payment channel, which is followed by credit cards, electronic cheques, charging cards and electronic money. The information derived from the table 6. Depicts the current e-payment systems ranking, which gives insight to the people tendency for conducting their money transactions. Debit and credit cards rank high among other e-payment systems because Iranian 
banks have proposed good internet bank services to pay and transfer money. In addition, they have equipped the bank branches, malls and markets with ATM machines all over the country, even in the smallest cities. Therefore, the people have a good accessibility to these e-payment systems in order to draw money or do other money transactions, like paying the bills and transferring money account-to-account through debit and credit cards. It is also worthy to mention that the debit and credit card e-payment systems in Iran are designed quite user friendly, so a great deal of money transactions, even the smallest ones, are preferred to be done through them. Although the Iranian banks facilitated using electronic cheques, this payment system is the next popular payment channel. According to the experts, as the amount of money paid by this kind of system is usually greater comparing to the small payments conducting by credit and debit cards for common daily payments, this leads to reduce the degree by which this payment system is used. According to the experts, using charging cards and electronic money are not very common because there are very little facilities provided to give people service in all country. Besides that, the other payment systems satisfy people's need.

\section{Conclusion}

When companies enter electronic commerce market, choosing an electronic payment system that works well with the way they run their business, which be both popular and safe, is a major concern. This research examined major criteria and current situation of e-payment systems in Iran. The AHP decision-making tool is used to rank the e-payment systems. In addition, the result of AHP method is discussed widely. The findings of this research are useful for both academic researchers and companies planning to adopt or to improve an electronic payment system.

\section{References}

Bryson, N. \& Joseph, A. (1999). Generating consensus priority point vectors: a logarithmic goal programming approach. Computers \& Operations Research, 26, 637-43.

Crawford, G. \& Williams, C. (1985). A note on the analysis of subjective judgment matrices. Journal of Mathematical Psychology, 29, 387-405.

Crede, A. (1998). Electronic Payment Systems, Electronic Money \& the Internet: The United Kingdom Experience to Date. TA-Datenbank-Nachrichten, 2, 29-39.

Hung, S. Y., Chang, C. M. \& Yu, T. J. (2006). Determinants of user acceptance of the e-Government services: The case of online tax filing and payment system. Government Information Quarterly, 23, 97-122.

Jing, Y. (2009). On-line Payment and Security of E-commerce. Proceedings of the 2009 International Symposium on Web Information Systems and Applications, 46-50.

Johnson, O. E. G. (1998). Payment systems, monetary policy, and the role of the central bank. Washington, DC. International Monetary Fund.

Khiaonarong, T. (2000). Electronic payment systems development in Thailand. International Journal of Information Management, 20, 59-72.

Lootsma, F. A. (1999). Multi-criteria decision analysis via ratio and difference judgment. Socio Economic Planning Sciences, 42, 192-197.

Saaty, T. L. (1980). The analytic hierarchy process: planning, priority setting and resource allocation. New York: McGraw-Hill.

Shim, J. P. (1989). Bibliographical research on the analytic hierarchy process (AHP). Socio Economic Planning Sciences, 23, 161-167.

Tsiakis, T. \& Sthephanides, G. (2005). The concept of security and trust in electronic payments. Computers and Security, 24, 10-15.

World Bank Report. (1990). Financial systems and development. World Bank Policy and Research Series. Washington, D.C.

Yu, H. C., His, K. H. \& Kou, P. J. (2002). Electronic Payment Systems: an analysis and comparison of types. Technology in Society, 24, 331-347. 